\title{
La embajadora roja: Alexandra Kollontai y México
}

\author{
The Red Ambassador: Alexandra Kollontai and Mexico
}

\section{Rina Ortiz Peralta}

CENTRO INAH VERACRUZ, rinaortiz@hotmail.com

Alexandra Kollontai fue embajadora de la Unión Soviética en México en 1926-1927, la memoria de su estancia se conserva en sus Diarios Diplomáticos, correspondencia y otros documentos. El examen de dichos materiales nos permite conocer las circunstancias de su nombramiento, su relación con el Partido Comunista Mexicano y también la forma como registró su encuentro con el país, su gobierno y habitantes.

Palabras Clave: Alexandra Kollontai, Internacional Comunista, Comunismo, Relaciones México-URSS.

Alexandra Kollontai was the Soviet Union's ambassador to Mexico in 1926-1927. The memoirs of her time there are conserved in her Diarios Diplomáticos (Diplomatic Diaries), correspondence and other documents. An analysis of these materials enlightens us as to the circumstances of her appointment, her relation with the Mexican Communist Party, and the way in which she recorded her encounter with the country, its government and its people.

KeYwords: Alexandra Kollontai, Communist International, communism, MexicoUSSR relations.

Fecha de recepción del artículo: 14 de mayo de 2016 / Fecha de aprobación: 12 de agosto de 2016 / Fecha de recepción de la versión final: 9 noviembre de 2016

a designación de Alexandra Kollontai como representante diplomática de la urss en Noruega en 1922 causó sensación en el mundo: no sólo porque era la primera vez que una mujer ocupaba un cargo así, sino por la extraordinaria personalidad de Alexandra Mijáilovna. Para entonces, era bien conocida por su lucha por la liberación femenina y la creación de un sistema de protección social para las madres e infantes, además de su participación en 
labores de agitación bolchevique. Durante veintitrés años, Alexandra Kollontai sirvió a la diplomacia soviética y, a lo largo de ese tiempo, anotó en varios cuadernos su experiencia; posteriormente transcribió, corrigió y pulió un manuscrito que depositó en 1949 en su archivo personal, resguardado en el entonces Archivo del Instituto de Marxismo-Leninismo (IML), ${ }^{1}$ con la indicación expresa de mantenerlo secreto y publicarlo hasta 1972, en el centenario de su natalicio. Hubieron de pasar, sin embargo, otras dos décadas para que sus diarios diplomáticos vieran la luz. ${ }^{2}$

En la larga carrera diplomática de Alexandra Kollontai, México ocupa un brevísimo espacio: apenas seis meses. De cualquier manera, su testimonio resulta interesante tanto por lo que señala explícitamente, como por aquello que apenas deja entrever o calla. No podemos olvidar que sus apuntes pertenecen a una época durante la cual en la uRss la crítica y disensión costaron la vida a muchos escritores y hombres públicos; ${ }^{3}$ pero donde también se sabía leer entre líneas. Así pues, la propia autora dejaba a las generaciones venideras la tarea de confrontar sus palabras con otras fuentes:

No me baso en documentos, en esto radica el valor de mis apuntes. Escribo sobre lo que yo misma vi, las personas que conocí y las impresiones que experimenté personalmente [...] Corresponderá a los historiadores del futuro comparar mis datos con los documentos de otros contemporáneos y sacar conclusiones. ${ }^{4}$

El propósito de este trabajo es examinar las circunstancias que propiciaron el nombramiento de Alexandra Kollontai como embajadora en México, las características de su misión y su relación con el

${ }^{1}$ Actualmente los materiales del ImL quedaron integrados en el Archivo Estatal Ruso de Historia Social y Política (RGASPI, por sus siglas en ruso). El fondo 134, Alexandra Mijáilovna Kollontai, conserva la mayor parte de sus manuscritos, correspondencia, recortes de prensa y fotografías.

${ }^{2}$ Alexandra Mijáilovna Kollontai, Diplomaticheskie dnevniki, 1922-1940 (Diarios diplomáticos, 1922-1940, 2 tomos (Moscú: Academia, 2001).

${ }^{3}$ Vitali Chentalinski, De los archivos literarios del KGB (Barcelona: Anaya \& Muchnik, 1994).

${ }^{4}$ Alexandra Mijáilovna Kollontai, Diplomaticheskie dnevniki, tomo I, 18. 
Partido Comunista Mexicano. Asimismo, presentaré la forma en que registró en su diario diplomático ${ }^{5}$ y otros documentos, su encuentro con el país, su gobierno y habitantes.

\section{LOS AÑOS PREVIOS}

“QQué, no quiere por nada ir a México?”, preguntó Stalin a Alexandra Kollontai, en la entrevista que sostuvieron el 6 de octubre de 1926 , a propósito de su nombramiento como embajadora en nuestro país. En efecto, ella se rehusaba a asumir un cargo que posiblemente la alejaría por largo tiempo de la uRss. Según relata la propia Kollontai en su correspondencia y diarios, una vez obtenido el reconocimiento de jure para la uRss, ella deseaba abandonar la labor diplomática en Noruega para reincorporarse al quehacer político, del que se había alejado paulatinamente después de la derrota de la "Oposición Obrera". Este grupo, encabezado por Alexander Schliapinikov, se había manifestado en contra de la creciente burocratización del Partido Comunista Ruso (bolchevique) PCR (b), y de la escasa presencia de los obreros en sus órganos de dirección. ${ }^{6}$ En el $\mathrm{x}$ Congreso del PCR (b), celebrado en marzo de 1921, el grupo presentó sus demandas, signadas también por Alexandra Mijáilovna. Los argumentos desplegados por la Oposición Obrera fueron rechazados tajante y sarcásticamente por Lenin en el Congreso. Pero sin darse por vencida, Kollontai los presentó nuevamente durante el III Congreso de la Internacional Comunista, efectuado en julio del mismo año. Su vehemente discurso no halló eco entre los delegados asistentes a la reunión, de modo que el fracaso del grupo disidente fue manifiesto; la decepción quedó registrada en su diario: "Yo sabía que esto sucedería. Pero me duele. Siento el alma sombría y llena de pena. No hay nada más doloroso que estar en desacuerdo con el partido" ${ }^{7}$

${ }^{5}$ Alexandra Mijáilovna Kollontai, Alexandra Kollontai en México. Diario y otros documentos, traducción, selección y notas de Rina Ortiz (México: Universidad Veracruzana, 2012).

${ }^{6}$ Alexandra Mijáilovna Kollontai, "Plataforma de la Oposición Obrera", en Autobiografía de una mujer emancipada, 4a edición (Barcelona: Editorial Fontamara, 1980), 185-256.

${ }^{7}$ Alexandra Mijáilovna Kollontai, Diplomaticheskie dnevniki, tomo I, 16. 
Este distanciamiento cerraba un periodo de intensa labor, iniciada desde el regreso de Alexandra Kollontai a Rusia a principios de 1917. Tras un largo exilio, volvía animada por las posibilidades de profundizar los cambios provocados por la Revolución de Febrero de 1917 y el derrocamiento del zarismo; llevaba consigo las Cartas desde lejos, escritas por Lenin en Suiza, para entregarlas al periódico Pravda. Siguieron meses de agitación política a favor de los bolcheviques, desplegando sus dotes de oradora en mítines con obreros, soldados y mujeres. Unos meses después, al triunfo de la Revolución de Octubre formó parte del primer gobierno soviético como Comisaria del Pueblo para la Seguridad Social, renunciando al cargo unos meses después por estar en desacuerdo con la firma del Tratado de Brest-Litovsk, que dejaba a Rusia fuera de la guerra y le imponía onerosas condiciones. A pesar de este primer conflicto con Lenin, ella continuó colaborando con el gobierno bolchevique en tareas de agitación y propaganda; en la organización de las mujeres; la creación de estancias infantiles y comedores públicos; así como también, a través de su pluma, difundiendo sus ideas acerca de la nueva moral; problemas como la prostitución; la alfabetización, el papel de las obreras y campesinas en la construcción económica, etcétera. Sus folletos alcanzaron tirajes de 150 mil ejemplares. ${ }^{8}$ Esta incesante actividad ha sido registrada pormenorizadamente por uno de sus biógrafos; ${ }^{9}$ aunque desafortunadamente, la mayor parte de los textos correspondientes a este periodo es prácticamente desconocida, pues, no volvieron a publicarse y sólo algunos de ellos han sido reproducidos en varias compilaciones. ${ }^{10}$ Por otra parte, llama la atención que, en el conjunto de sus memorias, el periodo 1917-1922

${ }^{8}$ Por ejemplo: Rabotnitsy, krestianki i krasny front (Las obreras, las campesinas y el frente rojo) (Moscú: 1920).

${ }^{9}$ Mijaíl Trush, Ot politiki revoliutsionnoi borb'y k pobedam na diplomaticheskom fronte. Zhizneniy put' Aleksandry Kollontai (De la lucha revolucionaria a los triunfos en el frente diplomático. La trayectoria de Alexandra Kollontai) (Moscú: Knizhniy Dom Librokom, 2010), 463-466.

${ }^{10}$ Alexandra Mijáilovna Kollontai, Izbrannye Stati i Rechi (Artículos y discursos selectos) (Moscú: Izdatelstvo Politicheskoi Literatury, 1972); Selected Articles and Speeches (Moscú: Progreso, 1984). Se trata de una versión reducida de la obra en ruso. 
reciba una atención casi marginal y que su escritura resienta su habitual espontaneidad y colorido en la expresión. ${ }^{11}$

Además de los desacuerdos con el partido, Alexandra Kollontai vivió en esa misma época un conflicto personal que le llevó a la ruptura con Pavel Dybenko, con quien había celebrado el primer matrimonio civil después de la revolución. El rompimiento la determinó a solicitar trabajar en el extranjero. Según ella misma refiere, hizo la petición directamente a Stalin, quien accedió a intervenir en su favor.

El desempeño diplomático de Alexandra Kollontai en Noruega fue bastante exitoso. Gracias a su anterior experiencia de vida en ese lugar, conocía el país y a los principales actores políticos. Pero a pesar de las satisfacciones, una vez conquistados los acuerdos más urgentes y el reconocimiento de la URSs, hizo todo lo posible por retornar a lo que verdaderamente le apasionaba: el trabajo entre las masas y la escritura. Tenía la esperanza de insertarse de nuevo en la actividad política, aunque sabía que su país atravesaba por una situación económica muy difícil y que al interior del partido bolchevique crecían las disensiones, a la par que la desconfianza, la persecución y el arresto de algunos de sus miembros más destacados. En 1923, mientras estaba de vacaciones en Moscú, ella misma fue víctima de la sospecha y padeció el acoso. Se le interrogó entonces acerca de sus relaciones con el denominado "Grupo obrero", formado por algunos de los miembros de la disuelta "Oposición Obrera”. Aunque no pudieron probar nada en su contra, en el informe de las autoridades sobre las declaraciones que le tomaron a Kollontai se señala: "el partido tiene derecho a no confiar a la camarada Kollontai el puesto de responsabilidad que ahora ostenta. La camarada Kollontai debe ser emplazada a regresar del extranjero y su caso debe ser revisado en el Comité Central del Partido". ${ }^{12}$ Al parecer Stalin intervino nuevamente en su favor y permaneció un tiempo más en Noruega, aunque siempre anhelando regresar a la URSS.

${ }^{11}$ Alexandra Mijáilovna Kollontai, Letopis moei zhizni (Crónica de mi vida) (Moscú: Academia 2004), 229-267; Iz moei zhizni i raboty (De mi vida y trabajo) (Moscú: Sovestskaya Rossia, 1974), 306-363.

${ }^{12}$ Leonid Mlechin, Kollontai (Moscú: Molodaya Gvardia, 2013), 237. 
El 31 de julio de 1925, Alexandra Mijáilovna escribió una carta muy personal a Maxim Litvinov, quien volvía a hacerse cargo del Ministerio de Relaciones Exteriores, comentándole que sus nervios necesitaban reposo y pidiéndole preparar al Colegio diplomático para que aceptara su renuncia: "Estoy cansada, moral y físicamente del eterno uniforme que exige este trabajo". ${ }^{13}$ Hubo de esperar un año más para volver, pero contra lo que esperaba, recibió un nuevo destino aún más lejano: México.

El 17 de septiembre de 1926, el Ministerio de Relaciones Exteriores de la URSS acordó remover de su cargo, como embajador en México, a Stanislav Pestkovsky, designando en su lugar a Alexandra Kollontai. ${ }^{14}$ La sustitución entrańaba un cambio en la política exterior soviética, hasta entonces estrechamente vinculada a la Internacional Comunista (IC o Comintern). La profundidad del cambio se hizo aún más patente el siguiente ańo, cuando el 28 de mayo de 1927 en sesión cerrada del Buró Político del PCR (b) se resolvió: "Excluir completamente del personal de las embajadas y representaciones comerciales a los delegados de la Sección Extranjera de la OGPU, ${ }^{15}$ de la Dirección General de Espionaje, del Comintern, Profintern y Socorro Rojo". ${ }^{16}$ Pestkovsky resulta, sin duda, una figura emblemática de este periodo ya que, paralelamente a su cargo diplomático fungía como enviado del Comintern. ${ }^{17}$ Precisamente por conducir sus empeños a promover la causa comunista, Pestkovsky no respondió a las expectativas del primer país americano que había establecido relaciones diplomáticas con el gobierno soviético. Lejos de ser un contrapeso a la constante presión que los Estados Unidos

${ }^{13}$ RGASPI, fondo 134, registro 1, exp. 344, f. 6 .

${ }^{14}$ RGASPI, fondo 134, registro 1, exp. 14, 1.

${ }^{15}$ OGPU: Ob’edinennoe Gosudarstvennoe Politicheskoe Upravlenie (Dirección Política Unificada del Estado), es decir, la policía secreta.

${ }^{16}$ Adibekov, G.M. Politburó TsK RKP(b)-VKP(b) i Komintern: 1919-1943. Dokumenty (Buró Politico del CC del PCR (b)-PCUS y Comintern: 1919-1943) (Moscú: ROSSPEN, 2004), 462.

${ }^{17}$ Lazar Jeifets y Victor Jeifets, “¿Quién diablos es Andrei? Stanislav Pestkovsky, Camarada Andrei: una tentativa de investigación histórica”, Memoria (121) (marzo de 1999): 21-26; Rina Ortiz, "Stanislav Stanislavovich Pestkovsky: diplomacia o subversión”, Diario de Campo, suplemento 55 (julio-septiembre 2009): 75-83. 
ejercían sobre el gobierno mexicano emanado de la reciente revolución, Pestkovsky parecía obstinado en encender nuevamente la mecha revolucionaria. Sus acciones y declaraciones habían creado una atmósfera tirante: por un lado, la embajada se había convertido en un lugar de reunión de los comunistas mexicanos y, por otro, Pestkovsky había llegado a afirmar que México constituía una base política muy conveniente para extender la influencia bolchevique en América. La Secretaría de Relaciones Exteriores de México presentó formalmente sus quejas. Ello, aunado al cambio en la política exterior soviética, tendiente ahora al fortalecimiento de la URSs, hizo inevitable la separación del incómodo embajador.

\section{Kollontai en MéXico. Reflejos de su diario}

Así, pues, en cierto sentido fueron las circunstancias las que determinaron la presencia de Alexandra Kollontai en México. Se le confiaba una tarea importante: abandonar la retórica acerca de la proximidad de las revoluciones rusa y mexicana, concentrándose en impulsar el fortalecimiento de la uRss. Stalin fue explícito: "En estos países es preciso seguir una política cautelosa, sin descuidar los principios, pero sin forzar los acontecimientos. Recuerde esto". ${ }^{18}$ Alexandra Mijáilovna lo tuvo siempre presente.

Antes de referirnos a los temas y personajes reflejados en su diario, quisiera exponer algunas de las características generales de estos materiales. Desde muy joven Alexandra Kollontai anotaba, en cuadernos y hojas sueltas, hechos y reflexiones sobre su acontecer cotidiano. Conservaba además recortes de periódicos, cartas, invitaciones, fotografías, carteles y otros documentos. En conjunto, todos esos materiales constituyen la base de los relatos autobiográficos y de los diarios diplomáticos que escribió y reescribió a lo largo de su vida.

Entre 1921 y 1945, Kollontai entregó a la imprenta diversos fragmentos de sus memorias, ${ }^{19}$ relativos a la etapa anterior a su acti-

${ }^{18}$ Alexandra Mijáilovna Kollontai, Alexandra Kollontai en México, 34.

${ }^{19}$ Alexandra Mijáilovna Kollontai, Iz moei zhizni i raboty (De mi vida y trabajo) (Odesa: Vseucrizdat, 1921), 77 p.; Otryvki iz dnevnika 1914 (Fragmentos del diario, 
vidad diplomática. Recientemente, trabajando con los materiales que aún conserva su familia, encontré una interesante nota de su secretaria particular, Emmi Lorenson, respecto del diario mexicano:

En 1947, Alexandra Mijáilovna propuso que se publicara esta parte del manuscrito ("México") en la revista Oktyabr. El escritor A. Pantieliev se encargaría de recortarlo y redactarlo de acuerdo a las normas editoriales. Sin embargo, la publicación no se llevó a cabo y el manuscrito fue devuelto. Alexandra Mijáilovna fue postergando el trabajo sobre sus memorias y después ya no alcanzó a restablecer el texto original del manuscrito de esta parte. $^{20}$

Resulta difícil saber hasta qué punto este hecho explique algunas ausencias en el diario, quizá la más significativa sea la de su relación con los comunistas mexicanos. ${ }^{21}$ Existen, sin embargo, indicios de que en la práctica no descuidó tampoco este aspecto.

El diario abre con un apartado titulado "Conversación con Stalin”, en el que Kollontai refiere sus vacilaciones sobre su adscripción a México y las instrucciones precisas que recibió:

En México la situación es compleja y es especialmente fácil cometer errores. Nosotros no estamos interesados en apoyar revueltas presuntamente revolucionarias, animadas y pagadas por los Estados Unidos. Los disturbios y rebeliones locales apuntalan la anarquía en México y resultan convenientes para los imperialistas en el país. Usted como representante de la Unión Soviética no debe sucumbir a la falsa idea de la proximidad de una revolución, de la cual México está todavía muy lejos. Su tarea como minis-

1914), (Gosizdat, 1924), 79 p.; "Souvenirs et Memoires autobiographiques", Bulletin Communiste (1-7, 9) (1925); "V tiurme Kerenskogo" ("En la cárcel de Kerenskii"), Katorga i Ssilka (7) (1927): 25-32; Den första etappen (Estocolmo: Bonniers, 1945).

${ }^{20}$ Nota de Emmi Lorenson, escrita en Peredelkino 20 de abril de 1989. Archivo Particular de la familia Kollontai.

${ }^{21}$ Desafortunadamente no he podido obtener copias de todos los materiales relativos a México que se encuentran en el fondo Kollontai del RGASPI. Existen varios expedientes con notas, informes, borradores de artículos, reflexiones sobre la efervescencia revolucionaria, cartas y otros materiales que en el futuro permitirán ahondar en este asunto. 
tro plenipotenciario consiste en fortalecer las relaciones normales de amistad entre la uRSS y México, no dejarse seducir por ninguna aventura revolucionaria". ${ }^{22}$

Era evidente, pues, que debía construir un nuevo tipo de relación con el Partido Comunista Mexicano.

Distanciarse de las prácticas establecidas por su antecesor fue quizá la primera dificultad a la que se enfrentó la nueva embajadora. A su arribo al puerto de Veracruz la esperaba un nutrido grupo de trabajadores, en su mayoría comunistas, que esperaban de ella un discurso. Kollontai juzgó inadmisible hacerlo, ante el asombro de León Jaikis, primer secretario de la Legación soviética, quien había demostrado gran afinidad con los métodos utilizados por Pestkovsky: "el camarada Pestkovsky, sin duda, los hubiera saludado", le comentó, pero ella no estaba dispuesta a seguir las huellas de quien la había precedido. ${ }^{23}$

La sombra del primer embajador estuvo presente durante algún tiempo: en el modesto hotel al que la condujo Jaikis; en el vagón de tercera que él había considerado adecuado para que la representante del país de los trabajadores viajara de Veracruz a la Ciudad de México; en la recepción que le habían preparado a su arribo a la estación de ferrocarril; en el pobre y escaso mobiliario de la embajada; en la falta de coche particular que la obligaba a fingir frente a los otros representantes diplomáticos que prefería caminar... Una austeridad, rayana en la miseria, que Pestkovsky había identificado como propia de un representante de los trabajadores. Poco a poco, Alexandra Mijáilovna impondría su propio sello.

\section{La atmósfera}

Como la propia Kollontai reconoce en el prólogo a sus diarios diplomáticos, en ellos no se encuentran revelaciones extraordinarias, son los apuntes de una observadora perspicaz y experimentada y

${ }^{22}$ Alexandra Mijáilovna Kollontai, Alexandra Kollontai en México, 33.

${ }^{23}$ Ibid., p. 45. 
también el ejercicio de una persona que disfruta escribiendo y conoce el deleite y peso de las palabras. ${ }^{24}$

El cuarto cuaderno de los diarios diplomáticos de Kollontai está dedicado a su estancia en México y aunque no contenga información confidencial, la narración refleja la atmósfera que reinaba en el país en esa época, así como el asombro de la autora frente a una realidad social enteramente distinta. Algunos de los temas constantes en el "diario mexicano" son los agravios a su persona, comenzando por la negativa de los Estados Unidos para concederle la visa de tránsito, la imposibilidad de desembarcar en la Habana y los continuos ataques en la prensa. Asimismo, menciona la presión que los Estados Unidos ejercían sobre el gobierno de Calles, así como las expresiones hechas contra la embajadora y el "peligro bolchevique".

Kollontai presentó sus cartas credenciales el 25 de diciembre de 1926 y fue bien recibida tanto por los funcionarios como por la opinión pública. El espléndido ramo de violetas que le envió el presidente Calles fue una elocuente muestra de buena voluntad. La cálida recepción parecía aliviar el malestar que le provocaba la altura y el estado en que encontró la embajada. Pero casi de inmediato, comenzaron los ataques a su persona en la prensa, tanto en la nacional como en la estadounidense.

Cuando Alexandra Mijáilovna llegó a México, se vivía una tensa relación con los Estados Unidos que por momentos hacía peligrar la frágil estabilidad política. La causa se hallaba, desde luego, en lo que consideraban una amenaza a los intereses económicos estadounidenses, ya que las reformas emprendidas por los gobiernos revolucionarios buscaban afianzar la soberanía, relegando los intereses de los propietarios mineros y petroleros extranjeros. ${ }^{25}$ Otro de los puntos de desconfianza era la política social, ya que en buena medida el

${ }^{24}$ Con frecuencia Alexandra Kollontai se refiere a su vocación de escritora, frustrada desde temprano. Aunque publicó algunos relatos, los temas y la calidad de su prosa han sido criticados. Véase por ejemplo: E. N. Stroganova, "O pisatelskoi drame Aleksandry Kollontai" (Acerca del drama de Alexandra Kollontai como escritora), en Teoria zhenskoi emansipatsii $v$ kontekste rossiskoi genderskoi politiki (Teoria de la emancipación femenina en el contexto de la politica rusa de género) (Tver: 2003).

${ }^{25}$ Lorenzo Meyer, Los grupos de presión extranjeros en el México Revolucionario, 19101940 (México: El Colegio de México, 2012), 63. 
gobierno contaba con el apoyo de amplios sectores populares gracias a la atención, aunque fuera parcial, de sus demandas. En la opinión pública estadounidense se presentaba al general Calles como bolchevique, identificándolo así con un radicalismo extremo. En enero de 1927, el secretario de Estado, Kellogg, presentó ante el Comité de Relaciones Exteriores del Senado Americano un memorándum declarando que eran evidentes las aspiraciones y la politica bolchevique de México en Centroamérica. Semejante declaración parecía confirmar los temores de Calles sobre una posible invasión estadounidense; el gobierno mexicano poseía documentos que apuntalaban esas presunciones y amenazó con exhibirlos. Pero mientras las negociaciones entre México y Estados Unidos proseguían, la embajadora soviética se convirtió en un blanco de ataques.

En esta tensa atmósfera se produjeron dos incidentes que ocasionaron fricciones y dejan ver la hostilidad a la que debió enfrentarse Kollontai para fortalecer las recién establecidas relaciones diplomáticas. El 14 de enero de 1927, el subsecretario de Relaciones Exteriores despachó al secretario de Gobernación una nota confidencial solicitando investigar "una cinta procedente de Rusia y de orientación marcadamente bolchevique, [enviada] para ponerle títulos en espańol con objeto de servirse de ella como medio de propaganda". ${ }^{26}$ Se giraron entonces las instrucciones pertinentes y el $22 \mathrm{del} \mathrm{mismo}$ mes El Universal publicó una nota en la que se revelaba el trasfondo del asunto: maniobras para hacer aparecer a México como centro de propaganda comunista. La nota refería la audiencia privada que el presidente Calles había concedido la víspera a la embajadora Kollontai, en la que ella había protestado por la campaña emprendida en los Estados Unidos en contra de la Legación Soviética acusándola de propagar ideas comunistas. La diplomática aseguró que "no pretende ni ha pretendido jamás mezclarse en los asuntos interiores de nuestro país, y que su principal labor está encaminada a establecer un intercambio comercial que permita a Rusia aprovechar nuestras materias primas". ${ }^{27}$

${ }^{26}$ AGN, fondo DGIPS, caja 16 , exp. 46, f. 1 .

${ }^{27}$ Ibid., f. 7. 
Algunos días después, el 28 de enero, la embajadora registra dicho incidente en su diario:

Primera entrevista oficial con el presidente Calles. Solicité una audiencia a propósito del escándalo periodístico en Estados Unidos que amarga mi existencia y está basado en las falsas revelaciones de Kellogg acerca de nuestra propaganda. Sus declaraciones son un embuste, calumnias contra nosotros impuestas por el odio al Estado proletario. No existe un solo hecho, ninguna evidencia seria. Pero la calumnia funciona. Los círculos de la gran burguesía mexicana la secundan. Todo esto es muy triste. ${ }^{28}$

Un par de meses después, en la prensa se armó un nuevo revuelo en relación con un ciclo de películas soviéticas que se presentaría en el Imperial Cinema. El 27 de marzo, el periódico Excélsior con el encabezado "Pérfida maniobra contra México por medio de propaganda cinematográfica", denunciaba que previo al estreno de la cinta "Bahía de la muerte" habían aparecido carteles anunciando la exhibición de la cinta como propaganda bolchevique autorizada por el gobierno mexicano. ${ }^{29}$ De inmediato, el Departamento Confidencial de la Secretaría de Gobernación giró un memorándum dirigido a los periódicos El Universal y Excélsior asegurando que el gobierno mexicano no había otorgado semejante autorización y que se tomaban ya las medidas contra "los autores de tan falaz imputación". Las autoridades detuvieron a Juan Bustillos Bridat, dueño del cine, y efectuaron las diligencias para averiguar quiénes habían ordenado semejante propaganda. Aprehendieron también a Adrián Devars, dueño de la imprenta El Libro Diario, ubicada en la calle de Mesones, donde se imprimió la propaganda supuestamente pagada por la embajada soviética. Alexandra Kollontai se entrevistó con el secretario de Relaciones Exteriores para aclarar la falsedad de las suposiciones y solicitar la liberación del dueño del cine para evitar que esto afectara futuros tratos. La averiguación duró unos días más, pero la información existente indica que realmente nunca se aclaró el asun-

\footnotetext{
${ }^{28}$ Alexandra Mijáilovna Kollontai, Alexandra Kollontai en México, 64.

${ }^{29}$ AGN, fondo DGIPS, caja 16, exp. 46, f. 14.
} 
to, ni se encontraron culpables. De cualquier manera, resulta interesante encontrar en el expediente una carta enviada desde Veracruz al secretario de Gobernación, Gral. Tejeda, solicitando intervenir en favor de Devars.

Unos días después, el 6 de abril de 1927, el subsecretario de Relaciones Exteriores se dirigió a la Secretaría de Gobernación, inquiriendo si se reanudaría la exhibición de las películas de Sovkino, ${ }^{30}$ al día siguiente se giraron instrucciones al presidente municipal de la Ciudad de México, con copia a Jaikis, autorizando la muestra de las películas, pues, "no son de propaganda bolchevique" como se quiso hacer ver de manera malévola. ${ }^{31}$ La presentación se reanudó después del 21 de abril.

En su diario Alexandra Kollontai conjetura que el caso de las películas estaba seguramente vinculado a un suceso acaecido algunos días antes. Cuenta que el 23 de marzo se encontraba en San Angel Inn, disfrutando de unos días de descanso cuya placidez quedó plasmada en la misiva a una amiga: “'Sabes desde dónde te escribo? Desde un monasterio. Sí, desde un antiguo monasterio español, convertido ahora en un restaurante y hotel en las afueras de la ciudad. [...] Por las mañanas y noches está vacío y es maravilloso. Gozo del silencio, además de mí y Pina hay uno o dos huéspedes" ${ }^{32} \mathrm{La}$ serenidad fue abruptamente interrumpida por el primer secretario Jaikis, quien le hizo saber que la esperaban en la Secretaría de Relaciones Exteriores. Ambos salieron precipitadamente hacia esa dependencia y en el camino ella dedujo que seguramente se trataba del apoyo monetario que los sindicatos soviéticos habían brindado a los ferrocarrileros en huelga. Efectivamente, el secretario Sáenz expresó que lamentaba el hecho considerándolo una acción en contra del gobierno, ya que éste había declarado la huelga ilegal. Así, pues, señaló que "Tomando en consideración los vínculos tan estrechos entre los sindicatos rusos y el gobierno soviético, el gobierno mexicano solicita al soviético ejercer su influencia sobre los sindicatos en este caso". Kollontai sorteó el asunto argumentando que los sindicatos

${ }^{30}$ AGN, DGIPS, Ibid., f. 11.

${ }^{31}$ Ibid., f. 24.

${ }^{32}$ RGASPI, fondo 134, reg. 1, exp. 311, f. 73. 
soviéticos ignoraban el carácter de la huelga, puesto que ella no había informado suficientemente sobre ese tema. Aunque el problema parecía zanjado, unos días después la cuestión "se desbordó de forma inesperada" con la suspensión de la muestra de las películas soviéticas. Así pues, la embajadora vio en ello parcialmente la mano del gobierno, como una forma de venganza por los 25 mil pesos que los sindicatos de la uRss habían enviado a los huelguistas ferrocarrileros mexicanos. En opinión de Kollontai, el asunto "era obra de la CROM. El incidente había ocurrido no sin el conocimiento del gobierno mexicano. De esta manera, Morones -secretario de Trabajo y Comercio- ajustaba cuentas con nosotros por la afrenta a la CROM". ${ }^{33}$ Efectivamente, más de una vez esta organización había denunciado la intromisión de los comunistas y el oro de Moscú. ${ }^{34}$

El incidente agravó los problemas de salud ocasionados por la altura de México y que en diversas ocasiones obligaron a Kollontai a guardar un reposo que ella consideraba contrario a su temperamento. Cuando ella le comentó el asunto al ministro de Relaciones Exteriores, Maxim Litvinov le propuso un nuevo destino para recuperarse, pero ella se negó a ser removida, precisamente para que ello no se interpretara como un nuevo viraje en la política soviética hacia México.

\section{Personas y lugares}

Entre las cualidades más notables de los apuntes de Kollontai destaca el trazo de la imagen de México: el retrato de sus habitantes, los lugares y personas que conoció, sus lecturas sobre la historia del país; en fin, el conjunto de apreciaciones positivas tendientes a fortalecer los vínculos entre la uRSS y México, que quedaron en el imaginario de ambas naciones y que llevaron a otorgarle la condecoración del Águila Azteca en 1946.

Tanto en su diario, como en su correspondencia, Alexandra Kollontai va registrando todo lo que llama su atención: la indumentaria, los colores, los aromas, la repentina caída de la noche... Su sutil

${ }^{33}$ Alexandra Kollontai, Alexandra Kollontai en México, 99.

${ }^{34}$ Jean Meyer, Historia de la revolución mexicana. Periodo 1924-1928. Estado y sociedad con Calles, tomo 11 (México: El Colegio de México, 1977), 163. 
pluma describe su arribo a Veracruz: "Sobre nuestras cabezas el azul del cielo no era intenso, sino lechoso, como desteñido. Los azules del golfo matan el color del cielo" ${ }^{35} \mathrm{Y}$ junto a esta imagen, apunta el desalińo que caracterizaba a Lev Jaikis, primer secretario de la embajada y la sorpresa frente a la multitud que la esperaba en el puerto: "Mujeres de rostros oscuros con vestidos de percal. Hombres con sombreros y overoles. Al frente se ve la hermosa figura de un negro de ébano, alto y que agita un pañuelo rojo".$^{36}$

Varias veces se refiere al cabello de las mujeres que "cual ala de cuervo, oscuro y espeso, [cae] completamente suelto sobre su espalda, como un manto negro" y menciona también los sarapes con que se embozan los hombres. La música es otro de los elementos de los que habla con frecuencia.

Subraya la cortesía y gallardía de los funcionarios con los que alterna. La fuerza que emana de la figura del general Calles, así como la antipatía que le produce Morones quien una y otra vez la hace esperar o de plano no la recibe.

El sol y el aire de la Ciudad de México parecen ser sus enconados enemigos. Hieren su piel y embotan su cabeza. Disfruta, en cambio, de los paseos por Reforma y Chapultepec, y las visitas al Sanborns, donde come mango a cucharadas como si fuera helado. Por cierto, la variedad de helados le fascina, lo mismo las frutas cuyos nombres anota cuidadosamente en un cuadernillo. Las salidas le permiten conocer formas de vida: "A ciertas horas del día, en Sanborns encuentras a todos, es decir, a intelectuales destacados, a periodistas, a diplomáticos". ${ }^{37}$

Y si en un principio asegura que no logra capturar todavía la naturaleza y todo le resulta ajeno, le agota la aridez y la falta de agua; cuando está en San Angel Inn o, más tarde, en Cuernavaca encuentra que son lugares "increíblemente" hermosos. En el hotel de San Angel Inn, disfruta tanto de platillos nuevos para ella, como de la conversación animada y enterada de su dueńa, la francesa Madame Roux. Hospedada en el hotel Borda Inn, escribe:

${ }^{35}$ Alexandra Kollontai, Alexandra Kollontai en México, 45.

${ }^{36}$ Ibidem.

${ }^{37}$ Ibid., p. 72. 
Aquí en Cuernavaca, de repente sentí que estaba en el trópico. Estamos en una región agrícola, los campos de maíz se encuentran en una extensa meseta entre montańas color violeta. ¡Pero lo mejor es el aire! Quieto, inmóvil, sin la menor brisa. El cielo es parejo, sin matices, no es brillante, sino más bien cristalino. Parece como si estuviéramos bajo una enorme cúpula de cristal, parecida a la tapa con que cubrimos el queso. Y como si todos en la tierra no fuéramos seres vivientes, sino figuras de cera: las palmeras inmóviles, los árboles de oscuro follaje, el grupo de indígenas de pies morenos y descalzos con sus sombreros de enormes alas, el débil chorro de la fuente que derrama en silencio gotas plateadas. Y también las flores rojas y brillantes en las lianas colgantes, nada se mueve. Todo está inerte. Todo quedó inmóvil en su brillante belleza teatral. ${ }^{38}$

También visita las escuelas rurales y las chozas de los campesinos, campesinos pobres que orgullosamente le muestran lo que producen. Las escuelas le llevan a reflexionar sobre el papel de la educación, repasa la visita a la Secretaría de Educación en la Ciudad de México donde se aprecian los murales de Diego Rivera con su particular visión de la historia. Varias páginas están dedicadas a lo que aprende sobre la historia de México, desde la época prehispánica hasta la reciente revolución, con héroes como Cuauhtémoc

cuya estatua se encuentra frecuentemente en las ciudades mexicanas [...] Fue él quien instaba a los indígenas a evitar compromisos con Cortés y quien contuvo a Moctezuma de entregar una posición tras otra. Cuando Cuauhtémoc se convenció de que Moctezuma se rendía ante Cortés, traicionando a su pueblo por honores, convirtiéndose prácticamente en un rehén respetado; Cuauhtémoc, amigo de Moctezuma, su colaborador siempre fiel, fue el primero que volvió su espada contra él. Moctezuma cayó a manos de sus propias tropas por perfidia, por traicionar a su pueblo [...] Es hermoso. Una especie de Bruto, pero más brillante. ${ }^{39}$

O como Zapata que permanece vivo en la memoria de los habitantes.

${ }^{38}$ Ibid., p. 108.

${ }^{39}$ Ibid., p. 115. 
Teotihuacán y la historia prehispánica le llaman poderosamente la atención.

Una impresión apasionante e inolvidable. Grandiosa e imponente. Qué maravillosa y monumental arquitectura, y al mismo tiempo, por la sencillez de sus líneas, tan afín a nosotros, al constructivismo. Son plazas cuadradas, los muros cónicos, una extraña combinación de triángulos. ¿No se habrá inspirado aquí el cubismo? ¡Qué dimensiones! El templo podía albergar hasta 15 mil personas. Teotihuacán no es solamente un templo, sino una ciudad enorme y majestuosa. Es la ciudad de una cultura original y desarrollada, asfixiada por los espańoles, especialmente los curas. ${ }^{40}$

En varias ocasiones se refiere a la guerra cristera que entonces se extendía en varios lugares de la república. Explica las razones que condujeron al conflicto: el apoyo de los curas a las fuerzas contrarrevolucionarias, su campańa contra las normas constitucionales y la respuesta de Calles expulsando a religiosos "extranjeros". "Esto provocó gran escándalo. Las escuelas religiosas están cerradas y se publicó un decreto para que los religiosos se registren civilmente. El alto clero emprendió una campańa en contra del gobierno mexicano. El mismo día en todo el país, los sacerdotes, ostentosamente, abandonaron los templos y se suspendieron los servicios religiosos" ${ }^{41}$

Entre los personajes que conoció sentía especial afecto por Manuel Puig Cassauranc, secretario de Educación Pública, con quien sostuvo largas conversaciones sobre la educación rural y los obstáculos que representaba el conflicto cristero para el avance educativo. Puig le presentó a la periodista Esperanza Velázquez Bringas con quien pudo compartir sus preocupaciones a favor de la liberación femenina.

Las fiestas y paseos populares, con su mezcla de personajes, colores y música, fascinaron a la embajadora.

${ }^{40}$ Ibid., p. 103.

${ }^{41}$ Ibid., p. 109. 
Me gustan las fiestas populares en México, los conciertos en el parque de Chapultepec o la fiesta en el estadio. Todos los domingos, desde las once de la mańana, en un tablado instalado en el lindero del parque, una pequeña y original orquesta interpreta melodías populares. Las cantantes, vestidas de china poblana, entonan canciones mexicanas. La orquesta es magnífica y las voces maravillosas. A los mexicanos les gusta la música y saben transmitirla. ${ }^{42}$

También la conmovieron la gracia y la habilidad con que montaban las mexicanas, así como su fogoso temperamento. La notable alegría que flotaba en las fiestas contrastaba, en su opinión, con la vida cotidiana de los mexicanos donde "son más bien reservados y melancólicos, como si tuvieran algún pesar”.

En muy poco tiempo, Alexandra Kollontai logró aquilatar la transformación que vivía México después de su revolución y distinguir a los actores que se movían en los diferentes entramados. Comprendió perfectamente la distancia que mediaba entre la revolución rusa y la mexicana y no se hacía ilusiones:

Nuestra presencia aquí es un castillo de arena. Esto se siente sobre todo cuando ocurren acontecimientos más o menos serios en el país, o cuando golpea la derecha. Además ni la sociedad ni el gobierno mexicano (aunque recientemente se ha debilitado un poco) han dejado de pensar que el sentido de nuestra presencia y nuestra tarea principal es hacer 'propaganda bolchevique' en todo el continente americano. ${ }^{43}$

Veía que la única manera de superar la desconfianza era establecer relaciones económicas sólidas, pero también sabía cuántos kilómetros separaban a los dos países.

Finalmente, Alexandra Kollontai miraba hacia el futuro del país de cara a las elecciones presidenciales del año siguiente, consideraba las posibilidades de la reelección de Obregón, pero también las pretensiones levantiscas de otros aspirantes. Sus apreciaciones políticas

${ }^{42}$ Ibid., p. 120.

${ }^{43}$ Ibid., p. 126. 
eran bastante acertadas, lo mismo que su juicio acerca de que en la Unión Soviética no se evaluaba correctamente el papel y significado de México.

Lo poco que sabemos del papel que juega México en América Latina impide extender nuestra influencia en el país y nos deja pasivos aun en aquellos casos en que, cautelosamente por supuesto, podríamos llevar una política más activa compensando las fuerzas imperialistas dominantes en México. En contraste, en los Estados Unidos comprenden muy bien que México es de hecho el "pionero", entre los países latinoamericanos, en la lucha contra el imperialismo. ${ }^{44}$

Así, la gestión diplomática de Kollontai podía considerarse exitosa al extender las posibilidades para el intercambio cultural y comercial, aun cuando los acuerdos comerciales que impulsó no llegaran a concretarse. Sin embargo, Kollontai no supo, o no pudo, transmitir a sus camaradas mexicanos la visión de conjunto que había formado.

\section{Los comunistas}

Alexandra Mijáilovna atendió escrupulosamente las instrucciones recibidas en relación con sus tareas diplomáticas y no encontramos en sus diarios indicios de una proximidad con los comunistas mexicanos, como la que había tenido su predecesor. Las alusiones a ellos son muy escuetas. Destaca, en primer lugar, su renuencia a hablar ante los grupos de camaradas que la esperaban tanto en Veracruz como en la Ciudad de México. Poco después subraya la necesidad de imponer una nueva relación, el 29 de diciembre escribe: "Es preciso que la embajada modere sus relaciones, demasiado marcadas con los comunistas locales; que el secretario de la embajada se conduzca como un diplomático y no como un organizador de partido". ${ }^{45}$ Pero el contacto era inevitable y no sin simpatía anota haber

${ }^{44}$ Ibid., p. 129.

${ }^{45}$ Alexandra Kollontai, Alexandra Kollontai en México, 59. 
conocido "a los camaradas más destacados de aquí. Monzón es muy bueno. Pedrueza, el teórico local, ha leído mis libros. Mis Abejitas ${ }^{46}$ se editan en Argentina”, pero añade que "de cualquier manera no está bien que los comunistas vengan con tanta frecuencia. No es conveniente. Sobre todo M. con su entusiasta esposa revolucionaria". ${ }^{47}$

La marcada distancia que pretendió imponer no implicaba que desatendiera aquellos elementos que pudieran apoyar el trabajo de otras dependencias abocadas a orientar el trabajo partidista. En primer lugar, comenzó a reunir información oficial que proporcionara elementos para comprender la situación del país de manera más completa, sin limitarse a los informes remitidos por el Partido Comunista Mexicano o por los que elaboraban, en sus breves estadías, los enviados de la Internacional Comunista. Tal es el sentido del Boletín Informativo que la embajada de la uRss comenzó a publicar en ruso en enero de 1927. Esta modesta edición mimeografiada tenía el objetivo de informar al Ministerio de Relaciones Exteriores de la URSS, "a los embajadores y otros camaradas, vinculados a la política exterior, a seguir el curso y los sucesos de la vida social y política de México". 48

Dibujos de Xavier Guerrero ilustran los tres números conocidos del Boletín, lo que da testimonio del vínculo de la embajadora con este pintor, aunque no lo mencione en sus memorias. En cambio, manifiesta no sentir ninguna simpatía por Diego Rivera, en quien encuentra "cierto cinismo vulgar", aunque reconoce su maestría: "Es un estilo especial. Moderno, pero al mismo tiempo único, una perspectiva propiamente mexicana de abordar el tema. En la pintura de Rivera hay una vehemencia revolucionaria, odio al capitalismo y a la hipocresía de la burguesía... Es sorprendente que en Europa conozcamos tan poco a Rivera". ${ }^{49}$ Es muy posible que conociera a Tina Modotti, ${ }^{50}$ uno de sus retratos parece haber sido hecho por la

${ }^{46}$ Se refiere a El amor de las abejas obreras (Barcelona: Alba Editorial, 2008).

${ }^{47}$ Alexandra Kollontai, Alexandra Kollontai en México, 60; M. es posiblemente Manuel Díaz Ramírez, cuya pareja en ese entonces era María del Refugio (Cuca) García.

${ }^{48}$ RGASPI, fondo 495, reg. 108, exp. 71, f. 2

${ }^{49}$ Alexandra Kollontai, Alexandra Kollontai en México, 113.

${ }^{50}$ En su libro Verdad y leyenda de Tina Modotti (México: Editorial Diana, 1992), 129, Christiane Barckhausen-Canale señala que Scheinis, uno de los biógrafos de Ko- 
italiana, al menos así lo señalan los familiares de Alexandra Mijáilovna. Por otra parte, algunas cartas de años posteriores permiten ver que mantuvo contacto con algunos de los personajes que conoció durante su permanencia en México, por ejemplo, Herón Proal o Rafael Ramos Pedrueza, para quien prologó La estrella roja: doce años de la vida soviética. ${ }^{51}$

Pero aunque en su diario Kollontai cuide sus juicios sobre la actividad del Partido Comunista Mexicano y las circunstancias en las que se desenvuelve, otros documentos revelan que, en los pocos meses que pasó en México, estudió la historia del país, evaluó a los diferentes actores políticos, sopesó la fuerza de los diferentes sectores sociales, procuró ver en perspectiva la estrategia seguida por los gobiernos posrevolucionarios, los límites de su discurso nacionalista, de las reformas emprendidas y sus posibilidades de maniobra frente a los intereses extranjeros. Los largos años de exilio la habían dotado de conocimiento y experiencia dentro del movimiento obrero y socialista europeo, además su periplo por los Estados Unidos durante la guerra le permitió acercarse a la entrańa de la principal potencia. Esa experiencia le permitió, sin duda, integrar un cuadro más cabal de México que presentaría posteriormente tanto al Ministerio de Relaciones Exteriores como a la Internacional Comunista.

Se ha sugerido que la presencia de Kollontai en México no representó una variación sustancial en la política exterior soviética, que su trabajo diplomático no demostró que se pudiera desvincular la diplomacia de la revolución, que su fracaso en este sentido determinó su salida. ${ }^{52}$

llontai le aseguraba que Alexandra Mijáilovna había tenido correspondencia con ella e incluso le había dedicado una fotografía. En el archivo de Kollontai no existen referencias al respecto y la fotografía en cuestión más bien parece dedicada a su amiga Tatiana Schepkiná-Kupérnik.

${ }^{51}$ RGASPI, fondo 134, reg.1, exp. 232, f. 1 .

${ }^{52}$ Victor y Lazar Jeifets, "Deitelnost sovietskij diplomatov kak faktor razvitia levogo dvizhenia Meksiki v 20 gody. Missiya Aleksandry Kollontai: smena vneshnego oblika ctaroi modeli" ("La actividad de los diplomáticos soviéticos como factor en el desarrollo del movimiento de izquierda en México en los ańos 20. La misión de Alexandra Kollontai: cambio exterior de un viejo modelo"), Mezhdunarodnie otnoshenia v novoe i noveishee vremiya. Las relaciones internacionales en la época moderna y contemporánea (San Petersburgo: 2005), http://www.history.pu.ru/biblioth/novhist/mono/vinogr/72.htm 
En mi opinión, su correspondencia tanto oficial como particular, así como sus diarios y notas, apuntan en otra dirección. Indudablemente uno de los motivos que la llevaron a solicitar su regreso fue su padecimiento cardiaco. Pero probablemente el más importante es que conocía los cambios que se estaban operando en la uRss y no quería permanecer al margen. Había sido testigo de cómo desde 1926 se había ido acallando la oposición interna dentro del PCR (b) y seguramente temía por su propia suerte y la de su hijo. ${ }^{53}$

No puede perderse de vista que el advenimiento de Stalin al poder significó cambios en la política del Comintern y, en consecuencia, en la línea que se trazaba para los partidos comunistas afiliados a esa organización. Dichos cambios se fueron reforzando paulatinamente, de modo que para 1927 dio inicio lo que se ha denominado el "giro a la izquierda", que fue alejando a los partidos comunistas de un frente común con otros movimientos sindicalistas, socialistas y de izquierda. ${ }^{54}$

Retomando el asunto de la visión particular que Kollontai se había formado sobre la situación en México y sus posibles repercusiones dentro de la Internacional Comunista, podemos considerar que en, cierta medida, sus puntos de vista reforzaron la idea de revisar a fondo el caso mexicano. Éste se había planteado por las divergencias que habían surgido entre Pestkovsky y algunos comunistas en relación con dos asuntos: el lugar que la dirección del PCM asignaba al campesinado en la transformación revolucionaria y los vínculos que sostenían algunos miembros del partido con líderes radicales como Adalberto Tejeda y Francisco Mújica, entre otros. El embajador Pestkovsky, en tanto que agente encubierto del Comintern, había llevado el conflicto al punto de expulsar a Manuel Díaz

${ }^{53}$ Alexandra Kollontai fue muy cuidadosa en sus expresiones sobre Stalin y, en general, sobre la historia soviética oficial. Es muy difícil saber cuántos de sus documentos desaparecieron cuando su archivo fue secuestrado, lo que es evidente es una autocensura en los materiales que la autora da a la prensa y también puede apreciarse en algunos artículos cómo se pliega a la línea marcada oficialmente.

${ }^{54}$ Horacio Crespo, "El comunismo mexicano en 1929: el 'giro a la izquierda' en la crisis de la Revolución”, en El comunismo: otras miradas desde América Latina, Elvira Concheiro et al., 559-584 (México: UnAM, 2007). 
Ramírez, dirigente del PCм y enlace principal con Alfred Stirner, funcionario de la IC y portavoz de los comunistas mexicanos ante dicha organización. En un principio, el asunto se presentó en términos de tomar en consideración las necesidades y la situación de cada país en particular, sin convertir las directrices generales emanadas de Moscú en una camisa de fuerza. A fin de evitar una escisión en el todavía débil Partido Comunista se requirió la presencia de Díaz Ramírez en Moscú para aclarar la situación y tomar una decisión adecuada. Sin embargo, la escasez de fondos impidió el viaje.

En tanto, sobrevino la remoción de Pestkovsky, que supuso, en cierto modo, una ventaja para la posición más flexible de Alfred Stirner, en ese momento era quizá quien mejor conocía México dentro del aparato de la Internacional Comunista. Eso se aunaba a la posición declarada por Stalin de dejar a los partidos en mayor libertad, alejando a los embajadores de toda intromisión. La denominada "cuestión mexicana" quedaba, pues, en suspenso. Sin embargo, dado que existían tareas urgentes que atender, Alexandra Kollontai buscó una solución:

La actividad se ha reanimado en América Latina y las tareas relacionadas con el congreso de la Liga Antiimperialista, demandan encarecidamente la presencia en América Central de uno de los nuestros, a través de quien y con cuya ayuda podamos llevar adelante el trabajo. Por ello, nuevamente planteo la cuestión de acelerar la llegada de un representante del Comintern. ¿Qué han decidido respecto del camarada Stirner? ${ }^{25}$

Los meses se sucedieron sin que hubiera una respuesta a este asunto. Pero la "cuestión mexicana" volvió a plantearse precisamente después del regreso de Kollontai a la uRss.

Los materiales consultados hasta el momento no nos permiten establecer con certeza cómo presentó Kollontai sus noticias sobre México en Moscú. Sabemos que pasó poco tiempo en la capital soviética, pues, había permanecido un tiempo en Berlín al lado de su hijo, de modo que quizá no pudo elaborar una comunicación ex-

${ }^{55}$ RGASPI, fondo 134, reg. 3, exp. 45, f. 3. 
tensa. Existen referencias sobre la elaboración de un informe en torno a la situación campesina, entregado y discutido en la Internacional Campesina (Krestintern).

En septiembre de 1927 se publicó en uno de los diarios soviéticos un artículo de Kollontai, titulado "México revolucionario" donde evoca con cierta nostalgia al país, describiendo su naturaleza y la riqueza de su historia y cultura; pero señalando también los retos a los que se enfrentaba:

la política de izquierda del actual gobierno mexicano, apoyado por los obreros y campesinos, provoca la irritada desaprobación de los imperialistas. No les gusta este "nido revolucionario" en el corazón mismo de América. No les gusta que, siguiendo el ejemplo de México, en su resistencia al imperialismo del Norte, se agiten y despierten las pequeñas repúblicas centroamericanas. ${ }^{56}$

El artículo hacía hincapié en la necesidad de promover el comercio entre la URss y México como el vehículo de acercamiento, es decir, la conclusión a la que había llegado al final de su estadía como embajadora.

Cuando este artículo vio la luz, Alexandra Kollontai ya se preparaba para viajar a Noruega en su nueva misión diplomática. Un mes después, en octubre de 1927, la Internacional Comunista envió una resolución sobre la posición que debía adoptar el PCM en relación con la política de Calles y la candidatura de Álvaro Obregón. Mientras tanto, Stirner preparaba un extenso informe sobre la situación en México, que contenía material estadístico y materiales suplementarios sobre la сRом. Dicho informe, presentado en diciembre de 1927, generó un importante debate, cuyas actas se abrieron hace poco a la consulta en los archivos rusos y que seguramente arrojarán nueva luz sobre este episodio de una historia todavía en construcción.

${ }^{56}$ Publicado en el periódico Vechernaya Moskva, 22 de septiembre de 1927, en Alexandra Mijáilovna Kollontai, Izbrannie stati i rechi (Artículos y discursos selectos) (Moscú: Politizdat, 1972), 359. 


\section{BIBLIOGRAFÍA}

Barckhausen-Canale, Christiane. Verdad y leyenda de Tina Modotti. México: Editorial Diana, 1992.

Cárdenas, Héctor. Historia de las relaciones entre México y Rusia. México: Secretaría de Relaciones Exteriores, Fondo de Cultura Económica, 1993.

Crespo, Horacio. "El comunismo mexicano en 1929: el 'giro a la izquierda' en la crisis de la Revolución”. En El comunismo: otras miradas desde América Latina. Elvira Concheiro et al., México: UNAM, 2007.

Chentalinski, Vitali. De los archivos literarios del KGB. Barcelona: Anaya \& Muchnik, 1994.

JEIFETS, Victor y Lazar. "Deitelnost sovietskij diplomatov kak faktor razvitia levogo dvizhenia Meksiki v 20 gody. Missiya Aleksandry Kollontai: smena vneshnego oblika ctaroi modeli" "La actividad de los diplomáticos soviéticos como factor en el desarrollo del movimiento de izquierda en México en los años 20. La misión de Alexandra Kollontai: cambio exterior de un viejo modelo"). En Mezhdunarodnie otnoshenia v novoe i noveishee vremiya. Las relaciones internacionales en la época moderna y contemporánea. San Petersburgo: 2005.

. “Quién diablos es Andrei? Stanislav Pestkovsky, Camarada Andrei: una tentativa de investigación histórica”. Memoria (121) (marzo de 1999): 21-26.

KollontaI, Alexandra Mijáilovna. Izbrannie stati i rechi (Artículos y discursos selectos). Moscú: Politizdat, 1972.

. Iz moei zhizni i raboty (De mi vida y trabajo). Moscú: Sovestskaya Rossia, 1974.

. "Plataforma de la Oposición Obrera". En Autobiografía de una mujer emancipada. 4a ed. Barcelona: Editorial Fontamara, 1980.

Selected Articles and Speeches. Versión reducida de la obra en ruso. Moscú: Progreso, 1984.

Diplomaticheskie dnevniki, 1922-1940 (Diarios diplomáticos, 1922-1940). 2 tomos. Moscú: Academia, 2001. 
. Alexandra Kollontai en México. Diario y otros documentos. Traducción, selección y notas de Rina Ortiz. México: Universidad Veracruzana, 2012. 2004.

. Letopis moei zhizni (Crónica de mi vida). Moscú: Academia,

Meyer, Jean. Historia de la revolución mexicana. Periodo 1924-1928. Estado y sociedad con Calles. Tomo 11. México: El Colegio de México, 1977.

Meyer, Lorenzo. Los grupos de presión extranjeros en el México Revolucionario, 1910-1940. México: El Colegio de México, 2012.

Mlechin, Leonid. Kollontai. Moscú: Molodaya Gvardia, 2013.

Ortiz, Rina. "Stanislav Stanislavovich Pestkovsky: diplomacia o subversión". Diario de Campo. Suplemento 55 (julio-septiembre 2009): 75-83.

Porter, Cathy. Alexandra Kollontai. A biography. Londres: Virago, 1980.

Stroganova, E. N. "O pisatelskoi drame Aleksandry Kollontai" (El drama de escritora de Alexandra Kollontai). En Teoria zhenskoi emansipatsii v kontekste possiskoi genderskoi politiki, (Teoría de la emancipación femenina ene le contexto de la politica rusa de género). Tver: 2003.

Trush, Mijaíl. Ot politiki revoliutsionnoi borby k pobedam na diplomaticheskom fronte. Zhizneniy put Aleksandry Kollontai (De la lucha revolucionaria a los triunfos en el frente diplomático. La trayectoria de Alexandra Kollontai). Moscú: Knizhniy Dom LIBROKOM, 2010. 